\title{
Essentials of electromagnetism
}




\section{MACMILLAN PHYSICAL SCIENCE}

\section{Series advisers}

Physics titles: $\quad$ Dr R L Havill, University of Sheffield

Dr A K Walton, University of Sheffield

Chemistry titles: Dr D M Adams, University of Leicester

Dr M Green University of York

Titles in the series

Group Theory for Chemists, $G$ Davidson

Thermal Physics, M Sprackling

Experimental Low-temperature Physics, $A$ Kent

Lanthanides and Actinides, $S$ Cotton

Introduction to Electrochemistry, $D B$ Hibbert 


\section{MACMILLAN PHYSICAL SCIENCE SERIES}

\section{Essentials of \\ electromagnetism}

David Dugdale

University of Keele 
(C) David Dugdale 1993

All rights reserved. No reproduction, copy or transmission of this publication may be made without written permission.

No paragraph of this publication may be reproduced, copied or transmitted save with written permission or in accordance with the provisions of the Copyright, Designs and Patents Act 1988, or under the terms of any licence permitting limited copying issued by the Copyright Licensing Agency, 90 Tottenham Court Road, London WIP 9HE.

Any person who does any unauthorised act in relation to this publication may be liable to criminal prosecution and civil claims for damages.

First published 1993 by

THE MACMILLAN PRESS LTD

Houndmills, Basingstoke, Hampshire RG21 2XS

and London

Companies and representatives

throughout the world

ISBN 978-0-333-56302-1

ISBN 978-1-349-22780-8 (eBook)

DOI 10.1007/978-1-349-22780-8

A catalogue record for this book is available

from the British Library 


\section{Contents}

List of physical constants and conversion factors

Preface

Acknowledgements

xi

xii

xiv

Chapter 1 Basic facts of electromagnetism 1

1.1 Introduction 1

1.2 Properties of electricity and magnetism 2

1.2.1 Units 6

1.2.2 Action at a distance and field theories 8

Problems

Chapter 2 Mathematical language of field theory 15

2.1 Scalar and vector fields 16

2.2 Differential changes of fields 16

2.2.1 Coordinate systems 18

2.3 Operator Del 21

2.4 Action of Del on vector fields 22

2.4.1 Scalar product and divergence 22

2.4.2 Vector product and Curl 24

2.5 Integration of fields 25

2.5.1 Line integrals 26

2.5.2 Surface integrals 30

2.5.3 Volume integrals 33

2.6 Translation of differential to integral forms 36

2.6.1 Divergence theorem 36

2.6.2 Stokes' theorem 39

2.7 Multiple operations with Del 43

2.8 Sufficiency of Div and Curl 46

Problems $\quad 48$

Chapter 3 Maxwell's equations in vacuo 51

3.1 Equations 51

3.2 Electromagnetic force 52 
3.3 General properties of Maxwell's equations 54

3.3.1 Gauss's law and Coulomb's law 54

3.3.2 Div $B=0$

3.3.3 Faraday's law and electromagnetic induction 57

3.3.4 Ampère's law and displacement current 62

3.3.5 Electromagnetic waves 66

3.3.6 Linearity and superposition $\quad 68$

$\begin{array}{ll}\text { Problems } & 68\end{array}$

Chapter 4 Electrostatics 71

4.1. Electric potential 71

4.2 Gravitational fields 74

4.3 Known charge distributions $\quad 76$

4.3.1 Spherically symmetric charge distributions $\quad 76$

4.3.2 Electric dipoles and quadrupoles 79

4.3.3 General solutions $\quad 85$

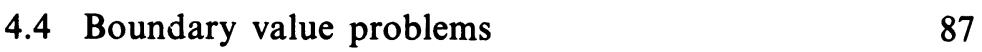

4.4.1 Electrically charged conductors 87

4.4.2 Uniqueness, shielding and earthing 90

4.4.3 Capacitance 93

4.4.4 Method of images 97

4.4.5 Numerical methods 105

4.5 Electrostatic energy 108

Problems 111

$\begin{array}{ll}\text { Chapter } 5 \text { Magnetostatics } & 115\end{array}$

5.1 Biot-Savart law $\quad 116$

5.2 Magnetic dipole $\quad 124$

5.3 Equivalent magnetic shell 131

5.4 Inductance 133

5.4.1 Self inductance 135

5.4.2 Mutual inductance $\quad 138$

5.4.3 Magnetic materials $\quad 140$

5.5 Magnetic vector potential $\quad 140$

5.6 Magnetostatic energy 142

5.6.1 Circuit interpretation $\quad 142$

5.6.2 Field interpretation 145

$\begin{array}{ll}\text { Problems } & 147\end{array}$

Chapter 6 Fields in material media 150

6.1 Macroscopic and microscopic fields 150

6.2 Polarisation 152

6.3 Magnetisation 158 
6.4 Maxwell's macroscopic equations

Chapter 7 Electrical properties of materials

7.1 Dielectric materials

7.1.1 Electric susceptibility and relative permittivity 169

7.1.2 Electrets and ferroelectrics 170

7.1.3 Electrostatics of dielectrics 171

7.1.4 Local fields and molecular polarisability 175

7.1.5 Electrostatic energy and dielectric materials 177

7.2. Conducting materials

7.2.1 Conductivity and resistivity

7.2.2 Resistance and conductance

7.2.3 Mobility of charge carriers

7.2.4 Hall effect

Problems

Chapter 8 Magnetic properties of materials

8.1 Atomic properties

8.1.1 Diamagnetism

8.1.2 Paramagnetism

190

8.1.3 Ferromagnetism

8.2 Magnetic susceptibility and relative permeability 192

8.3 Magnetostatics of magnetic materials 193

8.3.1 Inductors

8.3.2 Discs and rods

8.3.3 Spherical shell

8.4 Magnets

8.4.1 Hysteresis loops 198

8.4.2 Electromagnets 200

8.4.3 Permanent magnets 202

8.5 Magnetostatic energy and magnetic materials 205

8.5.1 Linear materials 205

8.5.2 Non-linear materials 206

Problems

Chapter 9 Electrical circuits $\quad \mathbf{2 1 0}$

9.1 Circuit elements 210

9.1.1 Ideal resistor 211

9.1.2 Ideal capacitor 212

9.1.3 Ideal inductor 213

9.1.4 Real circuit elements 214 
9.2.1 Real and ideal voltage generators 216

$\begin{array}{ll}9.3 \text { Circuit analysis } & 217\end{array}$

9.3.1 Kirchhoff's laws $\quad 217$

9.3.2 Distributed e.m.f. $\quad 219$

9.4 D.C. circuits 220

9.5 Transients 222

9.5.1 RC circuit $\quad 222$

9.5.2 $R L$ circuit 225

9.5.3 Energy storage in capacitors and inductors 226

9.5.4 Series $L C R$ circuit 227

Problems $\quad 229$

Chapter 10 A.C. circuits 231

10.1 Circuit analysis and phasor representations 232

10.2 Complex representations and impedance 235

10.3 Simple circuits 241

10.3.1 RC circuit 241

10.3.2 $R L$ circuit $\quad 242$

10.3.3 Series $L C R$ circuit $\quad 242$

10.3.4 Parallel $L C R$ circuit 245

10.4 Thévenin's and Norton's theorems 247

10.5 Transformers 249

10.6 A.C. bridges 253

10.7 High frequencies and stray capacitance 256

10.8 Transmission lines 257

10.8.1 Ladder networks 257

10.8.2 Continuous lines $\quad 259$

10.9 Limits of circuit theory 268

$\begin{array}{ll}\text { Problems } & 269\end{array}$

Chapter 11 Time-dependent fields and radiation 273

11.1 Electromagnetic potentials 274

11.2 Retarded potentials 276

11.3 Retarded fields 278

11.4 Linear current source 281

11.5 Electromagnetic waves 285

$\begin{array}{ll}\text { 11.5.1 Plane waves } & 285\end{array}$

11.5.2 Electromagnetic wave energy 288

11.5.3 Electromagnetic momentum 290

11.6 Waves in conducting media 292

11.6.1 Skin effect 292

11.6.2 Reflections from conducting surfaces 294 
11.7 Electromagnetic wave generation 295

11.7.1 Hertzian electric dipole 296

11.7.2 Half-wave dipole antenna 299

Problems

Chapter 12 Relativity and electromagnetism 305

12.1 Galilean transformation 305

12.2 Ether hypothesis 307

12.3 Lorentz transformations 309

12.3.1 Time dilation $\quad 310$

12.3.2 Lorentz contraction 311

12.3.3 Velocity transformation $\quad 312$

12.4 Relativistic mechanics 313

12.4.1 Energy and momentum 313

12.4.2 Relativistic force 314

12.5 Lorentz transformations in electromagnetism 315

12.5.1 Charge and current densities 315

12.5.2 Invariance of Maxwell's equations $\quad 317$

12.5.3 Linear charge distribution 319

12.5.4 Fields of a moving point charge 321

12.6 Dynamics of charged particles 322

12.6.1 Relativistic nature of the magnetic force 322

12.6.2 Uniform electric field 323

12.6.3 Uniform magnetic field 325

Problems

Appendix 1: Vector algebra 328

A1.1 Vector and scalar quantities 328

A1.2 Vector addition 328

A1.3 Products of vectors 329

A1.3.1 Scalar products $\quad 329$

A1.3.2 Vector products $\quad 330$

A1.4 Cartesian coordinate representations 331

A1.5 Triple products 332

Appendix 2: Spherical polar coordinates 333

A2.1 Unit vectors 333

A2.2 Vector operator $\nabla \quad 335$

A2.3 Divergence 335

A2.4 Curl 336

A2.5 Laplacian operator $\nabla^{2} \quad 336$ 
Appendix 3: Electromagnetic unit systems $\quad 337$

A3.1 M.K.S. and C.G.S. systems 337

A3.2 Current and charge units 338

A3.3 SI system 338

A3.4 C.G.S. systems 339

A3.4.1 Electrostatic units 339

A3.4.2 Electromagnetic units 339

A3.4.3 Gaussian units 340

Appendix 4: Distributed E.M.F. 343

Answers to problems $\quad 345$

$\begin{array}{ll}\text { Index } & 359\end{array}$ 


\section{List of physical constants and conversion factors}

\section{Physical constants}

Quantity

electric constant

(permittivity of free space)

magnetic constant

(permeability of free space) speed of light in a vacuum electronic charge electron rest mass proton rest mass Planck's constant

Bohr magneton Boltzmann's constant Avogadro's number
Symbol

$\varepsilon_{0}$
$\mu_{0}$
$c=\left(\varepsilon_{0} \mu_{0}\right)^{-1 / 2}$
$e$
$m_{\mathrm{e}}$
$m_{\mathrm{p}}$
$h$
$\hbar=h / 2 \pi$
$\mu_{\mathrm{B}}=\mathrm{e} \hbar / 2 m_{\mathrm{e}}$
$k$
$N_{\mathrm{A}}$

$\varepsilon_{0}$

$8.854 \times 10^{-12} \mathrm{Fm}^{-1}$

$4 \pi \times 10^{-7} \mathrm{Hm}^{-1}$

$2.998 \times 10^{8} \mathrm{~m} \mathrm{~s}^{-1}$

$1.602 \times 10^{-19} \mathrm{C}$

$9.109 \times 10^{-31} \mathrm{~kg}$

$1.673 \times 10^{-27} \mathrm{~kg}$

$6.626 \times 10^{-34} \mathrm{~J} \mathrm{~s}$

$1.055 \times 10^{-34} \mathrm{~J} \mathrm{~s}$

$9.274 \times 10^{-24} \mathrm{~A} \mathrm{~m}^{2}$

$1.381 \times 10^{-23} \mathrm{~J} \mathrm{~K}^{-1}$

$6.022 \times 10^{23} \mathrm{~mol}^{-1}$

\section{Conversion factors}

1 atomic mass unit $(\mathrm{u})=1.661 \times 10^{-27} \mathrm{~kg}$

1 electron volt $(\mathrm{eV})=1.602 \times 10^{-19} \mathrm{~J}$

1 Angstrom $(\AA) \quad=10^{-10} \mathrm{~m}$ 


\section{Preface}

This book presents an introduction to electromagnetism in a way that differs from that followed by most undergraduate texts. Usually such texts choose to follow a rather historically determined course. They advance along a broad front, slowly developing matters of fundamental principle (Maxwell's in vacuo field equations) side by side with technical applications and more phenomenological accounts of electromagnetism (Maxwell's equations in material media). Excellent though many of these texts are, the author believes that there is need of an alternative approach; one that presents a modern view of the unity of electromagnetism in as direct a way as possible. This book attempts to meet this need. It is based on lectures given in the joint honours physics course at Keele University.

The guiding principle here is the premise that 'electromagnetism is Maxwell's equations' in much the same way as, for example, 'Newton's laws are classical mechanics'. Just as a course on classical mechanics would be based at the outset on Newton's laws so here Maxwell's equations are introduced at the earliest opportunity, in order to serve as the basis for everything that follows. Electrostatics and Magnetostatics are treated as special cases of Maxwell's equations rather than as stepping stones leading to them. Similarly, the empirical laws on which the subject is founded, the laws of Coulomb, Ampère, Faraday, etc., are viewed as deductive consequences of Maxwell's equations rather than the other way round.

By forsaking the traditional historically ordered development for a more logically ordered one, the unity of electromagnetism can be made clear at an early stage. Since Maxwell's equations in vacuo are presented first, their physical significance can be fully discussed before introducing the phenomenological versions of these equations that apply to material media, thus allowing clearer distinctions to be made between microscopic and macroscopic fields. Despite these very worthwhile advantages it must be admitted that this approach involves a greater use of mathematical language at an earlier stage and this will be seen by some to be a significant disadvantage. Whether it is better to present all the 
mathematicai language of field theory (vector analysis) at the outset, as the present approach demands, or to develop it more slowly by distributing its presentation throughout the text, as the more traditional approach allows, is a matter of personal judgement. In the end the mathematics needed is the same whichever approach is followed and so for many the balance of advantage will favour the first option and the more intellectually stimulating approach to electromagnetism that it allows.

The numerical order of the chapters represents a more or less natural development of the subject, determined either by the fundamental significance of the material or by its practical importance. However, as the following flow diagram of logical connections shows, different orderings are possible. Circuit theory in chapters 9 and 10 could for example be treated after chapter 5 , or, as the broken line indicates, even earlier if the concepts of capacitance and inductance are dealt with first. For those students with sufficient prior knowledge of vector analysis, chapter 2 is not essential but still useful for reference purposes.

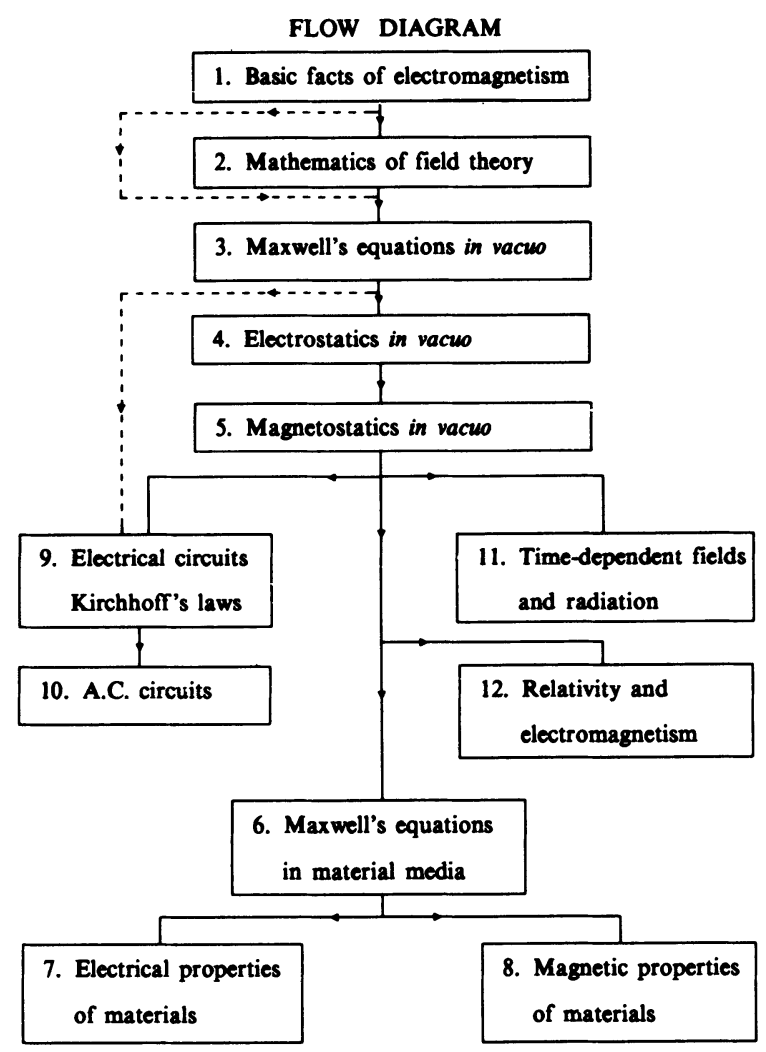




\section{Acknowledgements}

It is a pleasure to acknowledge the skilful work of my wife, Andrea, in the typing of the original manuscript and the help given by the advisers to the Macmillan Physical Science series, whose suggestions have lead to many improvements in the text. 